\title{
Solvent extraction applied to the recovery of heavy metals from galvanic sludge
}

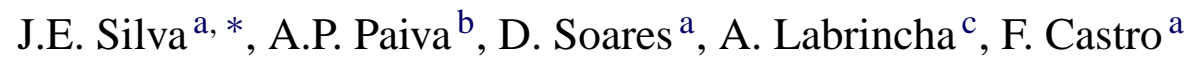 \\ a Mechanical Engineering Department, University of Minho, 4800-058 Guimarães, Portugal \\ ${ }^{\mathrm{b}}$ Department of Chemistry and Biochemistry, Centre of Chemistry and Biochemistry, Faculty of Sciences, University of Lisbon, 1749-016 Lisbon, Portugal \\ ${ }^{\mathrm{c}}$ Ceramics and Glass Engineering Department, CICECO, University of Aveiro, 3810-193 Aveiro, Portugal
}

Received 29 September 2004; received in revised form 7 December 2004; accepted 10 December 2004

\begin{abstract}
In this study, a hydrometallurgical treatment involving the solvent extraction and recovery of some heavy metals from a sulphuric acid leach solution of galvanic sludge, using di-(2-ethylhexyl)-phosphoric acid (D2EHPA) and bis-(2,4,4-trimethylpentyl)-phosphinic acid (Cyanex 272), both diluted in kerosene, has been investigated.

The preliminary tests revealed the necessity to remove other metal species than zinc and nickel, contained in the leach solution, and therefore, processes to cement copper and precipitate chromium were then applied to finally obtain a $\mathrm{Zn}$ and Ni pregnant solution prior to solvent extraction. For the experimental conditions studied, Cyanex 272 showed a good recovery of $\mathrm{Zn}$ after the stripping stage using $\mathrm{H}_{2} \mathrm{SO}_{4}$, but D2EHPA effectively promoted a higher Zn extraction than Cyanex 272 did. The dependence of the solvent extraction method on variables such as $\mathrm{pH}$, contact time and concentration of extractant, as well as the effect of different concentrations of sulphuric acid on stripping, are discussed.

The discussion also includes the previous conditions developed to separate the main interfering metallic species from the leach solution in order to improve the extraction and recovery of zinc by solvent extraction. The final objective has been to achieve a solution as pure as possible to recover nickel sulphate.
\end{abstract}

(C) 2004 Elsevier B.V. All rights reserved.

Keywords: Galvanic sludge; Metals extraction; D2EHPA; Cyanex 272

\section{Introduction}

It is extremely important to develop viable ways to recycle industrial sludge if either environmental or economical concerns are to be taken into account. Among the Portuguese industries, galvanic plants are usually those where the environmental problems caused by their effluents have serious repercussions. However, due to the actual economical condition of the country and also to the fact that the majority of these enterprises exhibit a small or medium dimension, this matter has rarely been considered a national priority to solve.

\footnotetext{
* Corresponding author. Tel.: +351 253510 220; fax: +351 253516007.

E-mail addresses: eudes@dem.uminho.pt (J.E. Silva), appaiva@fc.ul.pt (A.P. Paiva), jal@cv.ua.pt (A. Labrincha).
}

Nowadays, however, a lot of waste producers have begun to pay a greater attention to these effluent problems, trying to solve them as better as possible, due to the rising and stringent environmental regulations determined by an effective control policy. Unfortunately, the usual way to overcome the problem is frequently the disposal of the sludge as hazardous waste in special landfills located outside Portugal, since these residues do not have an accessible alternative treatment within the country. These wastes contain metals of interest like nickel, copper, zinc and others [1].

This disposal attitude leads to serious disadvantages, as it contributes to a great build up of environmentally hazardous materials on the earth's crust; on the other side, it does not consider the recovery of the heavy metals for re-use, which might represent an economy of raw materials and potential 
profits. Recent estimations point out to the generation of about 4000 and 150,000 tonnes/year of this kind of waste in Portugal and EU countries, respectively [2]. The dangerous character and eco-toxicity of these effluents are related with the high concentration of mobile/leachable metallic species, particularly the transition metals like chromium and nickel, which can rise up to 20 and 30\% (w/w, dry weight), respectively [2].

A good way to treat and recycle these materials can be the utilisation of the several hydrometallurgical technologies, the traditional and modern ones, since they are economical and environmentally suitable to recover valuable metal elements.

Solvent extraction is now a very well-established process in hydrometallurgy. It is used for the hydrometallurgical processing of copper, nickel, cobalt, zinc, uranium, molybdenum, tungsten, vanadium, rare earths, zirconium, hafnium, niobium, tantalum, indium, gallium, germanium, the platinum group metals, boron, reprocessing nuclear fuels, purification of wet process phosphoric acid, nitric acid recovery, etc. [3]. Nowadays, a very large number of stable extractants is available for use in hydrometallurgy, showing excellent selectivity for particular metal ions, coupled with advances in the engineering and increasing demands for higher purity products and more environmentally friendly processing routes [4].

Leaching of sludge coming from galvanic plants is mainly carried out using sulphuric acid solutions, the most abundant metallic species being nickel, chromium, copper, zinc, calcium and iron. From an economical point of view, nickel, zinc and copper are the most interesting metal values to recycle, but the toxicity allied to the high levels of chromium cannot be forgotten [5].

A literature survey covering the most recent information on the above metal separations reveals that organophosphorous acids are often the chosen extractants. Hence, di-(2ethylhexyl)-phosphoric acid (D2EHPA) allows an efficient recovery of $\mathrm{Zn}$ and $\mathrm{Cu}$ from sulphuric acid solutions of low $\mathrm{pH}(2.5-3.5)$. At this $\mathrm{pH}$, if Fe is present in the leach solution, it would be totally extracted [6-8]. Additionally, D2EHPA has also been employed to recover $\mathrm{Ni}$ from aqueous sulphate solutions (a pH of about 6-7 is necessary) [6,8-11]. Some works report an efficient separation of $\mathrm{Ni}$ from $\mathrm{Co}$ at lower $\mathrm{pH}$ values by the use of D2EHPA and Acorga M5640 (a hydroxyoxime derivative) [12], and D2EHPA and LIX 860 (a $\beta$-hydroxyaryloxime compound) [13]. Cr extraction from aqueous sulphuric acid solutions by D2EHPA has also been investigated [14]; and it was found that a $\mathrm{pH}$ varying between 3 and 4 is necessary to reach good extraction efficiencies. For an effective $\mathrm{Cr}$ recovery, however, the use of a modifier and a stripping mixture composed by $\mathrm{NaOH}$ and $\mathrm{H}_{2} \mathrm{O}_{2}$ is compulsory [14], whereas for all the other metals adequate $\mathrm{H}_{2} \mathrm{SO}_{4}$ or sulphate salt solutions have always resulted in good stripping efficiencies [6-11]. An additional work deserving a mention [15] refers to the use of D2EHPA or Ionquest 801 (a phosphonic acid derivative) to previously extract $\mathrm{Fe}$ and $\mathrm{Zn}$ from spent electroless nickel plating baths at $\mathrm{pH} 4$ and then LIX
84I (a $\beta$-hydroxyaryloxime) to finally recover $\mathrm{Ni}$ from the raffinate (for $\mathrm{pH}$ values higher than 6).

Another organophosphorous acid also reported to be quite suitable for these separation purposes is Cyanex 272 (its active ingredient is bis-(2,4,4-trimethylpentyl)-phosphinic acid). Several works report the adequacy of Cyanex 272 to extract, for instance, $\mathrm{Fe}, \mathrm{Zn}, \mathrm{Cr}, \mathrm{Cu}$ and $\mathrm{Ni}$ from sulphuric and/or sulphate solutions (their average $\mathrm{pH}_{0.5}$ being about 1.6, 3.0, 4.5, 4.6 and 7.05, respectively) [16-20]. A remarkable separation of Co from Ni using Cyanex 272 was also reported: for a $\mathrm{pH}$ of about $6,99.4 \%$ Co was extracted together with only $3 \%$ of $\mathrm{Ni}$ [21].

Generally it can be pointed out that Cyanex 272 needs higher $\mathrm{pH}$ values than D2EHPA to extract the same metal ions, this behaviour being explained by the fact that phosphinic acid derivatives are weaker acids than the phosphoric ones [6]. This acidity property is determinant if one takes into account that the metal ion extractions occur by their exchange with the acidic hydrogen atoms of the extractants, these latter being consequently released to the aqueous solution, decreasing therefore the equilibrium $\mathrm{pH}$ after extraction [6].

Although being an important basis for work, it should not be forgotten that most of the solvent extraction research referred to herein has been carried out with synthetic aqueous solutions. When leach solutions - frequently with much higher metal ion concentrations than those considered in synthetic ones - are obtained directly from industrial plants, the extraction systems become much more complex, as several equilibria established between the metallic species in the aqueous phases are likely to occur. Therefore, it is not strange that somehow different solvent extraction results from those already known for a given system could be obtained if "real" solutions are involved, this feature clearly justifying an additional point of interest of this research.

Jha et al. [22] made an extensive review concerning several industrial hydrometallurgical processes, including solvent extraction, to recover zinc from industrial wastes. Advances in the chemistry and engineering of industrial solvent extraction applied to the separation of $\mathrm{Ni} / \mathrm{Co}$ have also been cautiously described [23].

In this work, several aqueous solutions were obtained from sulphuric acid leaching of a polymetallic complex sludge, produced by a physicochemical treatment of wastewaters from a $\mathrm{Cr} / \mathrm{Ni}$ plating plant located in the north of Portugal. D2EHPA and Cyanex 272 were chosen as solvent extraction reagents, in an attempt to purify the leach solutions and allow the final recovery of nickel under the form of nickel sulphate.

\section{Experimental}

\subsection{Generation of leach samples}

All the leach samples (referenced therein as samples A-E) were generated from sulphuric acid leaching of a polymetallic 
complex sludge using a $100 \mathrm{~g} / \mathrm{L}$ sulphuric acid solution and a liquid to solid ratio (L/S) of 5:1 [24]. The sludge was produced by the physicochemical treatment of wastewaters from a Ni/Cr plating plant located at Braga, in the north of Portugal. The sludge, analysed by XRF, contained mainly $\mathrm{Ni}=9.46 \%$, $\mathrm{Cr}=7.04 \%, \mathrm{Cu}=4.19 \%$ and $\mathrm{Zn}=2.96 \%$ (w/w, dry weight) as metal elements of interest [24].

\subsection{Leach samples as aqueous feed in solvent extraction tests}

All the leach samples were previously neutralized through $\mathrm{pH}$ adjustment by the same kind of sludge (fresh, dried and ground $<1 \mathrm{~mm}$ ), used in the leaching stage, and filtered afterwards. The $\mathrm{pH}$ control of the aqueous samples, whenever necessary, was made with a WTW InoLab $\mathrm{pH}$ meter.

Di-(2-ethylhexyl)-phosphoric acid (93\% purity) was gently provided by Albright \& Wilson Americas Inc., and used as received. Cyanex 272 - bis-(2,4,4-trimethylpentyl)phosphinic acid, $80-87 \%$ purity - was kindly supplied by Cytec Canada Inc., and also used without further purification. Both extractants were diluted in kerosene (Fluka, purum, boiling point range $190-250^{\circ} \mathrm{C}$, without aromatics content).

Unless otherwise stated, the following conditions were generally adopted for the solvent extraction tests, carried out in stoppered flasks: extractant concentrations in the organic phase of $1 \mathrm{M}$, equal volumes of organic and aqueous solutions $(\mathrm{A} / \mathrm{O}=1)$, phase dispersion achieved by a stirring speed of $800 \mathrm{rpm}$ for a period of $60 \mathrm{~min}$. One molar sulphuric acid solution was generally used to regenerate the loaded organic phases. Stripping conditions were similar to the ones adopted in the extraction stage. After equilibration, the aqueous phases were always filtered to minimise organic contaminations. All the tests and analytical measurements were made at room temperature $\left(25^{\circ} \mathrm{C}\right)$.

Analyses of the metal contents in the aqueous solutions before and after extraction, and also of the stripping ones, were carried out by flame atomic absorption spectrometry (AAS) on a "GBC 904 AA" model. Metal concentrations in the organic solutions were calculated by mass balance.

\section{Results and discussion}

\subsection{Sample A}

The feed solution corresponding to sample A contained $\mathrm{Cr}=13.5 \mathrm{~g} / \mathrm{L}, \mathrm{Cu}=9.1 \mathrm{~g} / \mathrm{L}, \mathrm{Ni}=40 \mathrm{~g} / \mathrm{L}$ and $\mathrm{Zn}=7.6 \mathrm{~g} / \mathrm{L}$. Single-stage extraction tests at the initial $\mathrm{pH} 3.0$, using three different D2EHPA concentrations and four different contact times, were carried out according to the conditions shown in Table 1, in which the extraction percentages observed for the metal ions in the leach solution, after contact with $1 \mathrm{M}$ D2EHPA, are also included.

Under the adopted experimental conditions, Table 1 shows that only $\mathrm{Zn}$ was extracted with a significant extent, its ex-
Table 1

Preliminary D2EHPA extraction results obtained for the predominant metal ions contained in sample A

\begin{tabular}{lllll}
\hline Extraction conditions & \multicolumn{4}{l}{ Extraction $(\%)$} \\
\cline { 2 - 5 } & $\mathrm{Ni}$ & $\mathrm{Zn}$ & $\mathrm{Cu}$ & $\mathrm{Cr}$ \\
\hline $0.2 \mathrm{M} ; 1 \mathrm{~h}$ & 0 & 60 & 0 & 0 \\
$0.5 \mathrm{M} ; 1 \mathrm{~h}$ & 0 & 83 & 0 & 4 \\
$1.0 \mathrm{M} ; 1 \mathrm{~h}$ & 2 & 90 & 6 & 3 \\
$1.0 \mathrm{M} ; 3 \mathrm{~h}$ & 5 & 91 & 7 & 2 \\
$1.0 \mathrm{M} ; 8 \mathrm{~h}$ & 4 & 91 & 6 & 3 \\
$1.0 \mathrm{M} ; 24 \mathrm{~h}$ & 7 & 89 & 6 & 8 \\
\hline
\end{tabular}

traction increasing with the enhancement of D2EHPA concentrations. In addition, the contact time between both phases is not a relevant parameter, since $1 \mathrm{~h}$ is clearly enough for the system to achieve equilibrium. Also, based on literature data $[6,14]$, it was decided to reduce the equilibration period of extraction and stripping stages to $30 \mathrm{~min}$ in the subsequent solvent extraction tests.

\subsection{Sample B}

Second feed solution (sample B) contained $\mathrm{Cr}=18 \mathrm{~g} / \mathrm{L}$, $\mathrm{Cu}=12 \mathrm{~g} / \mathrm{L}, \mathrm{Ni}=39 \mathrm{~g} / \mathrm{L}$ and $\mathrm{Zn}=10.5 \mathrm{~g} / \mathrm{L}$, at an initial $\mathrm{pH}$ 3.5. Keeping in mind the good results presented by D2EHPA to extract $\mathrm{Zn}$ from sample A, under the followed experimental conditions, it was decided to test the solvent extraction behaviour shown by both D2EHPA and Cyanex 272 towards sample B, since this latter organic reagent was developed to extract preferentially Co to Ni from sulphate media $[16,18,20,21]$, as referred to earlier in Section 1. In fact, several papers in literature report that Cyanex 272 exhibits high extraction efficiencies for several transition metals when used in the correct conditions of $\mathrm{pH}$ range, contact time and concentration. Stripping of metals from loaded Cyanex 272 is usually very easy $[16,18,20,21]$. According to Lanagan and Ibana [17], the $\mathrm{pH}_{0.5}$ value observed for $\mathrm{Cr}$ (III) extraction by Cyanex 272 is of about 4.5, whereas the values shown by the same organic reagent towards $\mathrm{Zn}, \mathrm{Cu}$ and $\mathrm{Ni}$ extractions are $2.0,3.0$ and $\sim 6.5$, respectively, if the data reported by Rickelton et al. [18] is taken into account. Hence, a separation of $\mathrm{Zn}$ and $\mathrm{Cu}$ from Ni by Cyanex 272, at $\mathrm{pH}$ 3.0-4.0, could be expected.

Hence, for sample B, single-extraction stages performed with $1 \mathrm{M}$ D2EHPA and $1 \mathrm{M}$ Cyanex 272, with an initial $\mathrm{pH}$ value for the leach solution lowered to 3.0 by adding $\mathrm{H}_{2} \mathrm{SO}_{4}$ $1 \mathrm{M}$, were carried out, followed by another extraction stage, with the same extractant, applied to each of the raffinates after their neutralization with $\mathrm{CuO}$ until $\mathrm{pH} 4.0$ (the copper(I) oxide salt used for neutralization was processed from scraps in order to simulate more economical and environmentally suitable conditions).

Loaded organic phases from the extraction tests at $\mathrm{pH} 3.0$ and 4.0 , for each extractant, were stripped by equal volumes of $\mathrm{H}_{2} \mathrm{SO}_{4} 1 \mathrm{M}$. 
Table 2

Percentage of extraction of metal ions for sample B, by D2EHPA and Cyanex 272, for two different working pH values and their correspondent percentage of stripping from the loaded organic phases by $\mathrm{H}_{2} \mathrm{SO}_{4} 1 \mathrm{M}$

\begin{tabular}{|c|c|c|c|c|c|c|c|c|}
\hline & \multicolumn{4}{|c|}{ Using Cyanex $272(\%)$} & \multicolumn{4}{|c|}{ Using D2EHPA (\%) } \\
\hline & \multicolumn{2}{|c|}{ Extraction } & \multicolumn{2}{|c|}{ Stripping } & \multicolumn{2}{|c|}{ Extraction } & \multicolumn{2}{|c|}{ Stripping } \\
\hline & $\mathrm{pH} 3$ & $\mathrm{pH} 4$ & $\mathrm{pH} 3$ & $\mathrm{pH} 4$ & $\mathrm{pH} 3$ & $\mathrm{pH} 4$ & $\mathrm{pH} 3$ & $\mathrm{pH} 4$ \\
\hline $\mathrm{Cr}$ & 7 & 0 & 0 & 0 & 10 & 0 & 0 & 0 \\
\hline $\mathrm{Cu}$ & 0 & 0 & 0 & 0 & 0 & 20 & 0 & 50 \\
\hline $\mathrm{Ni}$ & 10 & 0 & 0 & 0 & 8 & 9 & 0 & 0 \\
\hline $\mathrm{Zn}$ & 40 & 80 & 60 & 95 & 80 & 95 & 40 & 60 \\
\hline
\end{tabular}

In Table 2, the percentages of total extraction and stripping of metal ions obtained for sample $\mathrm{B}$, at $\mathrm{pH} 3.0$ and 4.0, using D2EHPA and Cyanex 272, can be observed.

According to the results presented in Table 2, only Zn was again extracted with efficiency by both D2EHPA and Cyanex 272 , with more emphasis on the second extraction stage. Furthermore, some $\mathrm{Cu}$ was also extracted when D2EHPA was used, after the $\mathrm{pH}$ adjustment to 4 , and stripped in some extent by $1 \mathrm{M} \mathrm{H}_{2} \mathrm{SO}_{4}$, but this result can probably be due to the additional $\mathrm{Cu}$ coming from $\mathrm{CuO}$.

Anyway, it can generally be said that the increase of the $\mathrm{pH}$ values to 4 in the aqueous solutions, before the second extraction stage, resulted in an enhancement of the $\mathrm{Zn}$ and $\mathrm{Cu}$ extraction, this latter result verified only for D2EHPA. Moreover, although some $\mathrm{Cr}$ and $\mathrm{Ni}$ extraction was sometimes observed for both extractants, none of those metals was detected in the stripping phases.

Concerning the nature of the extractants, D2EHPA seems to be more effective than Cyanex 272 to recover $\mathrm{Zn}$, at least for the experimental conditions established, but Zn stripping from the latter reagent revealed to be easier.

As mentioned earlier, considering the information data reported in literature [16-20], it was expected that Cyanex 272 could show a good trend to co-extract $\mathrm{Zn}$ and $\mathrm{Cu}$, for the working $\mathrm{pH} \mathrm{4}$, reducing the number of metal species in the leach solution and thus its complexity. If that situation occurred, the next step would be to raise the working $\mathrm{pH}$ value of the feed solution to extract $\mathrm{Cr}$, in order to finally purify the solution with respect to the $\mathrm{Ni}$ content at a much higher $\mathrm{pH}$, again by use of Cyanex 272. However, the presence of several metal ions seems to lead to determinant changes in the equilibrium state of the solution. In fact, the overall results on the Cyanex 272 metal ion extraction behaviour published in literature were generally obtained with less concentrated and simpler synthetic solutions [16-20], therefore, providing a general and useful indication but not a guarantee of a successful application to "real" solutions. This has been indeed the case.

In view of the results displayed in Table 2, it was decided to test a pre-treatment of the feed solution by removing some metal species prior to solvent extraction. Since D2EHPA is cheaper than Cyanex 272 and showed better results for the leach samples tested, the former extractant was chosen to proceed in this investigation, although needing an improvement of performance for the stripping stage.

\subsection{Samples $C, D$ and $E$}

The main differences between samples A, B and C, D, and $\mathrm{E}$ are the order of magnitude of the concentrations of the metal species and the initial $\mathrm{pH}$ values. Table 3 presents the contents in $\mathrm{Cu}, \mathrm{Cr}, \mathrm{Ni}$ and $\mathrm{Zn}$ for all the leach samples, and their initial $\mathrm{pH}$ values, before treatment by solvent extraction. Such differences are due to the fact that the samples C, D and $\mathrm{E}$, in addition to their neutralization with sludge as described in Section 2.2, were then previously submitted to some stages of precipitation, namely a cementation process of $\mathrm{Cu}$ by using $\mathrm{Zn}$ dust and subsequent $\mathrm{Cr}$ removal by use of limestone. This latter treatment caused a raise in the $\mathrm{pH}$ values.

Almost $90 \% \mathrm{Cu}$ was recovered as metal powder from the cementation process, by applying $\mathrm{Zn}$ dust, for all the three samples. Moreover, it is now taking place the characterisation of the precipitate $\mathrm{Cr}-\mathrm{CaCO}_{3}$, as well as some tests, in order to study the viability of its application in refractory materials. Detailed conditions and results of these studies will be the target of a future paper.

Starting from the new feed solutions C, D and E, the aim is now to separate and recover $\mathrm{Zn}$ and Ni. For samples $\mathrm{C}$ and $\mathrm{D}$, feed solutions had their $\mathrm{pH}$ adjusted to $\mathrm{pH} 3.0$ by addition of $\mathrm{H}_{2} \mathrm{SO}_{4} 1 \mathrm{M}$.

\subsubsection{Sample $C$}

Zinc and nickel were extracted in two stages: firstly, a $\mathrm{pH}$ adjustment to 3.0 by addition of $\mathrm{H}_{2} \mathrm{SO}_{4} 1 \mathrm{M}$ was necessary and, after extraction, $\mathrm{NaOH} 1 \mathrm{M}$ was used to increase the $\mathrm{pH}$ value of the raffinate to 6 . In fact, it is known that $\mathrm{Zn}$ and

Table 3

Initial $\mathrm{pH}$ values and contents of the metal ions of interest contained in the overall leach samples A-E before treatment by solvent extraction

\begin{tabular}{lccccr}
\hline Sample & $\mathrm{pH}$ & \multicolumn{2}{c}{ Concentration $(\mathrm{g} / \mathrm{L})$} \\
\cline { 3 - 6 } & & $\mathrm{Cu}$ & $\mathrm{Cr}$ & $\mathrm{Ni}$ & $\mathrm{Zn}$ \\
\hline $\mathrm{A}$ & 3.0 & 9.1 & 13.5 & 40.0 & 7.6 \\
$\mathrm{~B}$ & 3.5 & 12.0 & 18.0 & 39.0 & 10.5 \\
$\mathrm{C}$ & 5.5 & 0.003 & 0.003 & 23.8 & 13.0 \\
$\mathrm{D}$ & 4.3 & 0.008 & 0.015 & 4.0 & 0.8 \\
$\mathrm{E}$ & 3.4 & 0.016 & 0.030 & 8.0 & 1.6 \\
\hline
\end{tabular}


Table 4

Percentages of D2EHPA extraction and $\mathrm{H}_{2} \mathrm{SO}_{4} 2 \mathrm{M}$ stripping, for $\mathrm{Zn}$ and $\mathrm{Ni}$, removed from sample $\mathrm{C}$

\begin{tabular}{|c|c|c|c|c|}
\hline & \multicolumn{2}{|c|}{ Extraction } & \multicolumn{2}{|c|}{ Stripping } \\
\hline & pH 3 & pH 6 & $\mathrm{Zn}$ & $\mathrm{Ni}$ \\
\hline $\mathrm{Zn}(\%)$ & 96 & $*$ & 88 & $*$ \\
\hline $\mathrm{Ni}(\%)$ & * & 63 & $*$ & 5 \\
\hline
\end{tabular}

* Concentration values under the detection limit.

$\mathrm{Ni}$ extractions by D2EHPA require an equilibrium $\mathrm{pH}$ of $\sim 3$ $[8,18]$ and $\sim 6$ [9], respectively. The extraction mechanism of $\mathrm{Zn}$ and $\mathrm{Ni}$ by acidic organophosphorus-based extractants obviously shows an inverse dependence on the acidity, hydrogen ions from the extractant being released during the extraction process. The loaded $\mathrm{Zn}$ and $\mathrm{Ni}$ ions were stripped from D2EHPA organic phases by $\mathrm{H}_{2} \mathrm{SO}_{4} 2 \mathrm{M}$, respectively.

Table 4 presents the percentage values of total extraction and stripping stages, for $\mathrm{Zn}$ and $\mathrm{Ni}$, removed from sample $\mathrm{C}$.

With the adopted procedure, a significant increase in $\mathrm{Zn}$ recovery has been accomplished, mainly due to a better performance attained in the $\mathrm{Zn}$ stripping stage by the $\mathrm{H}_{2} \mathrm{SO}_{4} 2 \mathrm{M}$ solution. Regarding the results obtained for $\mathrm{Ni}$, this metal ion was not extracted at lower $\mathrm{pH}$ values, as expected, but at $\mathrm{pH}$ 6 only a $63 \%$ extraction percentage was observed. Moreover, the final recovery of $\mathrm{Ni}$ stripped from the organic phase revealed to be quite low, that is, it has apparently not occurred. In the work reported by Sarma and Reddy [11], these researchers describe that the increase of sodium salt concentration in the feed solution resulted in a significant decrease in Ni extraction, mainly verified when D2EHPA was used, and this can probably be an explanation for the relatively low $\mathrm{Ni}$ extraction percentage observed herein.

\subsubsection{Samples $D$ and $E$}

After evaluation of the results obtained in the former test performed with sample $\mathrm{C}$, it was decided to optimize the $\mathrm{Zn}$ recovery by solvent extraction and try to maintain the maximum Ni content in the original solution. At the same time, a minimization of the use of D2EHPA was envisaged. Therefore, the $\mathrm{pH}$ of the sample $\mathrm{D}$ was lowered to 3.5 with $\mathrm{H}_{2} \mathrm{SO}_{4} 1 \mathrm{M}$ and both solutions $\mathrm{D}$ and $\mathrm{E}$ were treated with 0.5 M D2EHPA through single-extraction stages, the loaded organic phases being then stripped with $\mathrm{H}_{2} \mathrm{SO}_{4} 2 \mathrm{M}$ to reextract $\mathrm{Zn}$ ions.

Table 5 presents the percentages of extraction and stripping for $\mathrm{Zn}$ ions, and for $\mathrm{Ni}$ ions, from the samples $\mathrm{D}$ and $\mathrm{E}$.

Table 5

Percentages of D2EHPA extraction and $\mathrm{H}_{2} \mathrm{SO}_{4} 2 \mathrm{M}$ stripping, for $\mathrm{Zn}$ and $\mathrm{Ni}$, from samples D and $\mathrm{E}$

\begin{tabular}{llllll}
\hline & \multicolumn{2}{l}{ Sample D } & & & Sample E \\
\cline { 2 - 3 } \cline { 5 - 6 } & Extraction (\%) & Stripping (\%) & & Extraction (\%) & Stripping (\%) \\
\hline $\mathrm{Zn}$ & 100 & 100 & & 88 & 100 \\
$\mathrm{Ni}$ & 14 & 1 & & $*$ \\
\hline
\end{tabular}

* Concentration values under the detection limit.
The results displayed in Table 5 show a complete or close to full $\mathrm{Zn}$ recovery for the leach solutions containing lesser $\mathrm{Zn}$ and $\mathrm{Ni}$ contents than the previous ones, and the $\mathrm{Zn}$ quantitative stripping achieved from loaded D2EHPA phases also deserve a special mention. These $\mathrm{Zn}$ recovery values were obtained using half of the extractant concentration employed in the earlier tests.

\section{Conclusions}

A feed solution for a solvent extraction process, generated from the sulphuric acid leaching of a polymetallic complex sludge, with a $\mathrm{pH}$ adjusted to 3.5 and pregnant with $\mathrm{Ni}$ and Zn contents of about 10 and $2 \mathrm{~g} / \mathrm{L}$, respectively, seems suitable for the recovery of $\mathrm{Zn}$ using D2EHPA as extractant. The optimization of the stripping process with $\mathrm{H}_{2} \mathrm{SO}_{4} 2 \mathrm{M}$ allowed the recovery of almost all the zinc present in the organic phase. However, preliminary precipitation stages to remove $\mathrm{Cu}$ and $\mathrm{Cr}$ are advisable. Finally, nickel sulphate can be produced from the quite pure raffinate solvent extraction aqueous solution by the salt crystallization method.

Concerning the $\mathrm{Cu}$ and $\mathrm{Cr}$ metal species, almost $90 \% \mathrm{Cu}$ was recovered as metal powder by the cementation process through the use of $\mathrm{Zn}$ dust, whereas at the moment the characterisation of the $\mathrm{Cr}-\mathrm{CaCO}_{3}$ precipitate takes place, as well as some tests, aiming to its probable application in ceramic materials. Detailed conditions and results of this research will be the target of a paper to be prepared soon.

\section{References}

[1] D.A. Pássaro, Report: waste management in Portugal between 1996 and 2002, Waste Manage. 23 (2003) 97-99.

[2] Magalhães, J.A., Inertization of galvanic sludge by its incorporation in ceramic bodies, Ph.D. Thesis, University of Minho, 2002.

[3] D.S. Flett, Review—new reagents or new ways with old reagents, J. Chem. Technol. Biotechnol. 74 (1999) 99-105.

[4] K.C. Sole, Solvent extraction and ion exchange, in: Short Course: Hydrometallurgy HYDRO 2003, 2003 International Symposium on Hydrometallurgy, 22-24 August 2003, Vancouver, Canada, 2003.

[5] J.M. Magalhães, J.E. Silva, F.C. Castro, J.A. Labrincha, Role of the mixing conditions and composition of galvanic sludges on the inertization process in clay-based ceramics, J. Hazard. Mater. 106B (2003) 139-147.

[6] M. Cox, Solvent extraction in hydrometallurgy, in: J. Rydberg, C. Musikas, G.R. Choppin (Eds.), Principles and Practices of Solvent Extraction, Marcel Dekker Inc., New York, 1992, pp. 357-412.

[7] P.M. Cole, K.C. Sole, Solvent extraction in the primary and secondary processing of zinc, in: K.C. Sole, P.M. Cole, J.S. Preston, D.J. Robinson (Eds.), Proceedings of the International Solvent Extraction Conference ISEC 2002, vol. 2, 17-21 March 2002, Cape Town, South Africa, Chris van Rensburg Publications (Pty) Ltd., 2002, pp. 863-870.

[8] K. Kongolo, M.D. Mwema, A.N. Banza, E. Gock, Cobalt and zinc recovery from copper sulphate solution by solvent extraction, Miner. Eng. 16 (2003) 1371-1374.

[9] Y.C. Cheng, Purification of synthetic laterite leach solution by solvent extraction using D2EHPA, Hydrometallurgy 56 (2000) 369-386. 
[10] B.R. Reddy, P.V.R.B. Sarma, Transfer of nickel from sodium sulphate solutions to the spent electrolyte through solvent extraction and stripping, Hydrometallurgy 60 (2001) 123-128.

[11] P.V.R.B. Sarma, B.R. Reddy, Liquid-liquid extraction of nickel at macro-level concentration from sulphate/chloride solutions using phosphoric acid based extractants, Miner. Eng. 15 (2002) 461-464.

[12] A. Cerpa, F.J. Alguacil, Separation of cobalt and nickel from acidic sulfate solutions using mixtures of di(2-ethylhexyl) phosphoric acid (DP-8R) and hydroxyoxime (ACORGA M5640), J. Chem. Technol. Biotechnol. 79 (2004) 455-460.

[13] F.J. Alguacil, Solvent Extraction with DP-8R/LIX 860 mixtures for the selective separation of cobalt and nickel, Rev. Metalurgia 38 (2002) 205-209.

[14] D. de Juan, V. Meseguer, L.J. Lozano, Chromium extraction with organic solvents. Part 1: Extraction with DEHPA, Rev. Metalurgia 34 (1998) 253-260.

[15] M. Tanaka, M. Kobayashi, T. Seki, Recovery of nickel from spent electroless nickel plating baths by solvent extraction, in: K.C. Sole, P.M. Cole, J.S. Preston, D.J. Robinson (Eds.), Proceedings of the International Solvent Extraction Conference ISEC 2002, vol. 2, 17-21 March 2002, Cape Town, South Africa, Chris van Rensburg Publications (Pty) Ltd., 2002, pp. 787-792.

[16] W.A. Rickelton, D. Nucciarone, The treatment of cobalt/nickel solutions using CYANEX ${ }^{\circledR}$ extractants. Hydrometallurgy and refining of nickel and cobalt, in: W.C. Cooper, I. Mihaylov (Eds.), Proceedings of the Nickel-Cobalt 97 International Symposium, vol. I, August 17-20, Sudbury, Ont., Canada, 1997, pp. 275-292.

[17] M.D. Lanagan, D.C. Ibana, The solvent extraction and stripping of chromium with Cyanex 272, Miner. Eng. 16 (2003) 237-245.
[18] W.A. Rickelton, D.S. Flett, D.W. West, Cobalt-nickel separation by solvent extraction with bis(2,4,4-trimethylpentyl) phosphinic acid, Solvent Extr. Ion Exch. 2 (6) (1984) 815-838.

[19] B.R. Reddy, P.V.R.B. Sarma, Separation and recovery of cobalt and nickel from sulfate solutions of Indian Ocean nodules using Cyanex 272, Miner. Metall. Process. 18 (2001) 172-176.

[20] D. Nucciarone, B. Jakovljevic, B.A. Fir Medeiros, J. Hillhouse, M. DePalo, Extraction of selected metal cations with the alkylarylphosphinic acid: 2,4,4-trimethylpentylphenylphosphinic acid, in: K.C. Sole, P.M. Cole, J.S. Preston, D.J. Robinson (Eds.), Proceedings of the International Solvent Extraction Conference ISEC 2002, vol. 1, 17-21 March 2002, Cape Town, South Africa, Chris van Rensburg Publications (Pty) Ltd., 2002, pp. 402-407.

[21] E.G. Liranza, A.M. Daudinot, R.V. Martínez, B.R. Bárzaga, Separation of cobalt and nickel by solvent extraction from sulfate liquors obtained by acid leaching of a product from the Caron process, in: K.C. Sole, P.M. Cole, J.S. Preston, D.J. Robinson (Eds.), Proceedings of the International Solvent Extraction Conference ISEC 2002, vol. 2, 17-21 March 2002, Cape Town, South Africa, Chris van Rensburg Publications (Pty) Ltd., 2002, pp. 952-957.

[22] M.K. Jha, V. Kumar, R.J. Singh, Review of hydrometallurgical recovery of zinc from industrial wastes, Resour., Conserv. Recycl. 33 (2001) $1-22$.

[23] I. Mihaylov, Solvent extractants for nickel and cobalt: new opportunities in aqueous processing, JOM 55 (7) (2003) 38-42.

[24] Silva, J.E., Paiva, A.P., Soares, D., Labrincha, J.A., Castro, F.C., Leaching behaviour of a galvanic sludge in sulphuric acidic and ammoniacal media. J. Hazard. Mater., submitted for publication. 